\title{
A Ética Profissional como fator influenciador nas Organizações
}

\author{
Anay Furini Dias ${ }^{1}$; Paloma da Silva Nitsche ${ }^{2}$; Liliane Gomes de Paula \\ Anna Ariane Araújo de Lavor ${ }^{4}$; Antônio Carlos Alves da Silva ${ }^{5}$ :Mariana Emídio Oliveira Ribeiro ${ }^{6}$
}

\begin{abstract}
Resumo: Este artigo buscou apresentar a importância da ética e da moral nas organizações e demonstrando sua contribuição para o sucesso empresarial. Ética é o nome dado ao ramo da filosofia dedicado aos assuntos morais. A palavra ética é derivada do grego, e significa aquilo que pertence ao caráter, acompanhando a sociedade nos dias de hoje percebe-se a necessidade dos valores morais em todas as esferas sociais, dessa maneira ocorrendo uma redescoberta da ética num contexto social com crise de valores, falta de respeito e decoro. Para um sucesso em longo prazo, as empresas devem primar por decisões e relações que permeiam em seu íntimo a ética profissional, as empresas têm função social no desenvolvimento da comunidade e sua atuação ética lhe proporciona reconhecimento e ela se torna importante no crescimento da sociedade. Foram feitas consultas em várias fontes, livros de diferentes autores e plataformas de artigos bibliográficos, foram utilizados o método de pesquisa qualitativa e exploratória que teve como objetivo a procura de uma base de conhecimentos. A pesquisa abordada trouxe um amplo conhecimento sobre as empresas nas quais priorizam e aplicam em suma o código de ética, levando em consideração o reconhecimento e a preservação dos princípios, aumentando a confiabilidade com os indivíduos em que se relacionam.
\end{abstract}

Palavras-chave: Ética, Moral, Organizações, Sociedade.

\section{Professional Ethics as an Influencing Factor in Organizations}

\begin{abstract}
Abastract: This article will present the importance of ethics and morals in organizations while demonstrating their contribution to business success. Ethics is the name given to the branch of philosophy dedicated to moral affairs. The word ethics is derived from the Greek, and means what belongs to the character, accompanying the society in the present day perceives the need for moral values in all social spheres, thus occurring a rediscovery of ethics in a social context with crisis of Values, lack of respect and decorum. For a long-term success, companies must excel in decisions and relationships that permeate the professional ethic in their hearts, companies have a social function in the development of the community and their ethical performance provides them with recognition and it becomes important in the growth of society. We consulted in several sources, books of different authors and platforms of bibliographical articles, we used the method of qualitative and exploratory research that had as objective the search of a knowledge base. The research presented brought a wide knowledge about the companies in which they prioritize and apply in short the code of ethics, taking into consideration the recognition and preservation of the principles, increasing the reliability with the individuals in which they relate.
\end{abstract}

Keywords: Ethics, Moral, Organizations, Society.

\footnotetext{
1,2,3 Graduando em Administração pela Faculdade de Alta Floresta-FAF.

${ }^{4}$ Mestranda em Ambiente e Desenvolvimento pala UNIVATES. Contato: annaariane@ hotmail.com;

${ }^{5}$ Mestrando em Ambiente e Desenvolvimento pala UNIVATES. Contato: acas-acas@ hotmail.com;

${ }^{6}$ Mestranda em Ambiente e Desenvolvimento pala UNIVATES. Contato: mariana_meo@hotmail.com;
} 


\section{Introdução}

A falta de ética na sociedade atual tem-se mostrado cada vez mais nítida, pessoas com queixas frequentes sobre a falta de ética em todas áreas, seja na política, na indústria, nos meios esportivos, religiosos e culturais. A sociedade moderna em muitos casos, valoriza mais os comportamentos de podem excluir qualquer outra probabilidade de cultivo de relações éticas.

É fácil verificar, portanto, na mídia, nas redes sociais, o desejo e a vontade muitas vezes obsessiva na aquisição, no poder e no consumo de bens materiais, o qual tem sido valorizado e adquirido o prestígio social as pessoas que possuem tais bens. Dessa maneira, o sucesso financeiro e material passou a representar sucesso profissional e social, assim como o sucesso pessoal que também deve ser conquistado a todo o momento.

O sentido amplo da Ética é o estudo do comportamento humano perante seus semelhantes, o qual analisa a aprovação ou desaprovação da ação dos homens. A Ética descreve as ações do ser humano coletivamente e individualmente estudando o desempenho e comportamento individual e coletivo dentro da comunidade em que se insere,buscando criar uma conduta adequada perante a sociedade, tendo como objeto de estudo os valores e o bem.

A definição da Ética vem com esclarecimento da teoria de fundamento último do agir humano em busca do bem comum e da realização indiviual. Para Valls (1993, p.7) "a ética é daquelas coisas que todo mundo sabe o que são, mas que não são fáceis de explicar, quando alguém pergunta".

As pessoas não nascem com a ética ou a moral, formam-se com o passardos anos, sendo influenciadas pelas famílias e a sociedade. O tema: Ética profissional como um fator influenciador nas organizações vem sendo discutido ao longo dos anos, notando a ênfase na conduta ética dos profissionais, a prática da conduta dentro das organizações são de suma importância, colaborando assim no desempenho das mesmas.

A moral empresarial é o conjunto dos valores e normas que são utilizados dentro das empresas, buscando ter uma convivência harmônica no grupo profissional, a ética profissional reflete sobre normas e valores predominantes dentro das organizações. As empresas procuram funcionários de boa índole com uma boa relação com os clientes e com a equipe de trabalho. 
"Tendo em vista os valores morais nota-se que sua relevância na atmosfera corporativa e empresarial tem estado deturpada, a atividade ineficaz da autoridade e o poder corrupto abalam a vontade de uma ação balizada nos bons costumes" (NALINI, 2014, p. 31).

O essencial é reconhecer que hoje se evidência reabilitar a ética em toda a sua compreensão e alcance, pois a crise da humanidade é uma crise de ordem moral, os descaminhos da criatura humana, refletidos na violência, na exclusão, no egoísmo e na indiferença pela sorte do semelhante, assentam-se na perda de valores morais, alimentam-se da frouxidão de conduta.

A insensibilidade no trato com a natureza denota a contaminação da consciência humana pelo vírus da mais cruel insensatez. A humanidade escolheu o suicídio ao destruir seu habitat. É paradoxal assistir à proclamação enfática dos direitos humanos, simultânea a intensificação do desrespeito por todos eles.

Os critérios de aprendizagem dentro dos conceitos da moral e da ética vêm sendo aperfeiçoados. Em atenção a importância dos bons costumes no ambiente corporativo o presente artigo tem por problemática: Como a Ética profissional e a moral influenciam nas organizações?. Os objetivos que nortearam a pesquisa foram: Identificar os fatores influenciadores da Ética profissional nas empresas; verificar a importância da Ética profissional e da moral, com enfoque na ética interna da empresa; demonstrar a relação dos conceitos de ética e moral.

Godim, (2005, p.6), define a ética como o estudo geral do que é bom ou mal, para o autor um dos objetivos da ética é a busca de justificativa para as regras propostas pela moral, é distinto, pois, diz que a moral estabelece regras que são assumidas pelas pessoas como uma forma de garantir o seu bem-viver a moral depende das fronteiras geográficas e garante uma identidade entre pessoas que se quer se conhece, mas utilizam este mesmo referencial comum.

No contexto organizacional atual, a importância das empresas em prezar pelo respeito às pessoas se ampliou, pois a corrupção, negligência e omissão são lesões às virtudes e não podem ser justificadas nas práticas institucionais violando os valores do homem.

\section{Embasamento Teórico}


Antes de falar, conceituar e discutir sobre a ética e sobre a moral deve-se, relacionar assuntos de comprometimento profissional. Autores afirmam sobre a profissão e carreiras de profissionais de diversas áreas, bem como o seu comprometimento com a empresa e com a carreira.

Steers (1977) diz que quando o indivíduo possui alta titulação, ou seja, quanto maior for o nível de educação, maior será o seu comprometimento com a carreira, e quanto menor o nível de educação mais comprometimento o indivíduo tem com a empresa.

Segundo Cortella (2009, p. 102), a ética é "o que marca a fronteira da nossa convivência". [...] "é aquela perspectiva para olharmos os nossos princípios e os nossos valores para existirmos juntos [...]" é o "conjunto de seus princípios e valores que orientam a minha conduta". O homem, ao viver em sociedade e ao conviver com outros seres de sua espécie, dito, outros homens, deve ter a ideia de como agir socialmente e como se comportar de acordo as regras de conduta moral.

A ética é uma condição de resposta ao convívio dos seres humanos, aos aflitos em família e ligada aos costumes individual. Segundo Chalita (2009, p.27): "O ser humano busca a felicidade, desde que surgiu no mundo e se reconheceu capaz de produzir cultura e transformar o ambiente em que vive”. Essa busca, no entanto, faz parte das energias fundamentais que movem o espírito humano.

Aristóteles já sabia disso, há mais de dois milênios. Mesmo na obscuridade das antigas cavernas, subjugados aos penosos os afazeres de caçar seu alimento e coletar frutas e folhas da natureza, nossos ancestrais marcavam a sua diferença atávica dos outros animais por um atributo muito simples, muito singelo, mas fundamental: a habilidade de sorrir.

No meio empresarial a ética está ligada as normas e valores impostos pelas organizações, ser ético é saber agir de maneira correta nas relações sociais.No cotidiano as pessoas conduzem nos relacionamentos em sociedade comportamentos influenciados pelas condições que tem a seu redor, seus valores e crenças individuais, balizados por uma convivência pacífica, a qual constitui o objetivo da ética (LISBOA, 2010). 
Id on Line Revista Multidisciplinar e de Psicoloqia

Id on Line Multidisciplinary and Psycology Journal

Quadro 1 - Diferenças sobre a Ética e a Moral.

\begin{tabular}{|l|l|}
\hline \multicolumn{2}{|l|}{\begin{tabular}{l} 
MORAL \\
\hline Modo social de agir diante a sociedade
\end{tabular}} \\
\hline Validade restrita ao Estado & Modo pessoal de agir, formada ao logo da vida \\
\hline Normas e regras sociais & Abrangência universal \\
\hline $\begin{array}{l}\text { Coletivo: se constrói a partir do consenso de } \\
\text { várias morais }\end{array}$ & Normas e regras pessoais \\
\hline É regra & Individual: é o que fundamenta a ética \\
\hline Trata-se de bem/mal & Conduta da regra \\
\hline
\end{tabular}

Fonte: Elaboração própria

Se as empresa agirem de forma ética, podem estabelecer normas de condutas para que seus dirigentes e empregados, exigindo que ajam com lealdade e dedicação (DENNY, 2001, p.276).

Nalini (2014, p. 58) enfatiza que "a ética é justamente saber discernir entre o devido e o indevido, o bom e o mau, o bem e o mal, o correto e oincorreto, o certo e o errado", tendo em vista a grande busca e importância da ética e da moral dentro da sociedade e principalmente dentro do âmbito empresarial, a ética pode ser considerada a ciência dos costumes, e seu objetivo principal é a moral, a ética pode ser considerada uma moralidade positiva, um conjunto de regras de comportamento, as quais levam o homem a realizar os valores do bem, demasiadamente enfatiza:

As organizações éticas buscam, na prática, ser honestas, justas e verdadeiras e democráticas, por uma questão de princípio e não de convivências, muito embora este tipo de agir lhes traga também sucesso e reconhecimento. Sua forma de ser inspira a confiança e a credibilidade dos indivíduos com quem se relacionam e assim, seu empenho e lealdade (Passos, 2011, p. 92).

Efetivamente as empresas procuramser democráticas e justas, tendo em vista, melhorias no convívio interpessoal entre seus gestores, colaboradores e clientes, portanto, Aguilar (1996 apud PASSOS, 2011, p. 93) classifica a empresa ética como: 
Aquela que conquistou o respeito e a confiança dos seus empregados, clientes, fornecedores, investidores e outros, estabelecendo um equilíbrio aceitável entre seus interesses econômicos e os interesses de todas as partes afetadas, quando toma decisões ou empreende ações (AGUILAR apud PASSOS, 2011, p. 93).

Certamente a empresa alcançará uma posição de destaque no mercado competitivo, do mesmo modo, na visão de Leisinger e Schmitt (2001, p. 18):

\begin{abstract}
Moral por um lado, se manifesta pelo fato de determinada conduta humana ser considerada "boa" ou "má". Com isso é expresso um valor ou desvalor; por conseguinte, a moral orienta-se por valores. Porém, para realizar a moral não suficiente emitir juízos de valores a respeito de uma determinação [...] as normas já pressupõe os valores..., o que as normas exigem é que os valores sejam realizados (SCHMITT, 2001, p. 18).
\end{abstract}

Haja vista, com os crescentes casos de corrupção e falta de decoro existentes dentro dos setores públicos e privados, que são noticiados quase que diariamente, nota se que a ética e a moral estão sendo cada vez mais almejadas dentro da sociedade e na conduta de seus gestores e colaboradores, visto que no intuito de proporcionar o bom relacionamento entre as pessoas torna-se necessário o estabelecimento de regras que conduzam o respeito entre os integrantes da sociedade, por sua vez a implantação de normas e regras possibilita a conservação dos princípios da instituição, posteriormente, Nalini (2014, p. 420) descreve:

\footnotetext{
As empresas, por conhecerem o mercado, são hábeis ao descobrir o anseio por ética. Sentem o clamor da população desiludida com o governo, desconfiada de toda atuação pública, a exigir compostura e retidão de conduta. Se conseguem preencher esse vácuo moral com atuação reconhecida pelos parceiros agregarão ao valor intrínseco daquilo que produzem - bens ou serviços - um capital efetivo (NALINI, 2014, p. 420).
}

Tendo em vista os comportamentos inadequados pelos gestores e colaboradores, anseia-se por mais atitudes e comportamentos balizados pela moral e ética, Vazquez (1995, p. 55) defende que "a função social da moral consiste na regulamentação das relações entre os homens (entre os indivíduos e entre o indivíduo e a comunidade) para contribuir assim no sentido de manter e garantir uma determinada ordem social".

Pode-se analisar que para que as organizações possam aplicar de maneira eficaz conceitos éticos e morais junto aos seus colaboradores, é preciso que seja estabelecida uma 
ética interna da organização que oriente suas decisões e permeiem suas relações com a sociedade em geral, destaca Leisinger e Schmitt (2001, p. 54):

Se uma empresa pode ser considerada como um "coletivo" moral depende antes de tudo do grau de liberdade de ação que ela deixa aos seus membros. Só nas organizações em que as pessoas podem decidir livremente entre várias opções de ação é que uma responsabilidade individual pode ser assumida. Quando não existe a liberdade de ação, ou quando ela é muito pequena, então as virtudes dos membros individuais da organização deixam de ocupar o primeiro plano da análise ética, sendo substituídas pela rigidez da estrutura organizacional e pelos princípios diretores da organização (LEISINGER; SCHMITT, 2001, p. 54).

Verifica-se que as instituições assim como as outras instâncias adotam normas coletivas, e os indivíduos que atuam como colaboradores tendem a passar por experiências de adaptações, como destaca Leisinger e Schmitt (2001, p.55):

\begin{abstract}
As empresas, como também outras estruturas sociais, são instâncias de socialização através das quais os indivíduos experimentam uma adaptação a determinadas exigências de papeis sociais e de conduta". Se neste amplo processo de adaptação a personalidade e a consciência pessoal se perdem nas normas coletivas quando as pessoas internalizam e imitam os papeis dos "outros significativos (LEISINGER; SCHMITT, 2001, p. 55).
\end{abstract}

Deste modo, as empresas precisam estar atentas as adaptações das vivências de cada colaborador com a ética profissional da organização, buscando harmonia na relação institucional e também no relacionamento com o público em geral, pois atualmenteos clientes demonstram estar mais exigentes, buscam organizações com condutas e comportamentos retos, que tenham atitude ética em seus negócios, e as empresas atentas a estas exigências têm a seu favor a credibilidade e confiança de seus clientes, proporcionando sucesso a ela no mercado, além de dispor de um ambiente de trabalho mais agradável e funcionários satisfeitos (NALINI, 2014).

Reiterando o pensamento acima Vazquez (1995, p. 56):

A moral implica, portanto, numa relação livre e consciente entre os indivíduos ou entre estes e a comunidade.Mas esta relação está também socialmente condicionada, precisamente porque o individuo é um ser social ou um nexo de relações sociais. o indivíduo se comporta moralmente no quadro de certas relações e condições sociais determinadas que ele não escolheu,e dentro também de um sistema e de princípios, valores e normas morais que não inventou, mas que recebe socialmente e segundo o qual regula as suas relações com os demais ou com a comunidade inteira (VAZQUEZ, 1995, p. 56) 
É necessário que a organização equilibre os comportamentos morais induviduais de sua equipe com sua ética profissional buscando confiabilidade do público alvo e boa visibilidade no mercado,Ashley (2006) demonstra que é necessário a atenção das empresas para as responsabilidades éticas e morais, pois envolvem uma gama de normas, regras, intenções de comportamento para atender ao público alvo da organização, os valores morais podem ter variações com o meio social, e esses definem o que é ser ético e as empresas utilizam para demonstrarem ser corretas e justas.

\title{
Metodologia
}

Foi utilizado no procedimento metodológico a pesquisa bibliográfica, buscando em livros a fonte de coleta de informações, referenciais teóricos, bem como foram acessadas as plataformas Scielo, Capes e Sucupira e o site administradores.com.br.

A pesquisa utilizada foi a qualitativa realizada no segundo semestre do ano de 2016, a pesquisa qualitativa "não se preocupa com representatividade numérica, mas, sim, com o aprofundamento da compreensão de um grupo social, de uma organização" (GERHARDT; SILVEIRA, 2009, p. 31).

A pesquisa é exploratória, pois, buscou-se criar uma base de conhecimentos sobre o tema estudado. Dessa maneira, segundo Gil (2008) o objetivo principal é elucidar e mudar conceitos e ideias. Todavia, é uma pesquisa que foi desenvolvida com o intuito de proporcionar uma visão geral e ampla sobre a ética profissional.

Para Cervo, Bervian e Silva (2007, p. 63 e 64),

\begin{abstract}
A pesquisa exploratória realiza descrições precisas da situação e quer descobrir as relações existentes entre seus elementos componentes. Esse tipo de pesquisa requer um planejamento bastante flexível para possibilitar a consideração dos mais diversos aspectos de um problema ou de uma situação. Recomenda-se a pesquisa exploratória quando há pouco conhecimento sobre o problema a ser estudado (CERVO; BERVIAN; SILVA; 2007, p. 63 e 64).
\end{abstract}

A análise de dados foi análise textual discursiva, com base na sistemática sugerida por Moraes (2003, p. 192), “[...] pode ser compreendida como um processo auto organizado de 
construção de compreensão em que novos entendimentos emergem de uma sequência recursiva de três componentes: a unitarização; a categorização; e a nova compreensão é comunicada e validada".

\section{Resultados e Discussão}

Esta pesquisa teve como finalidade identificar os fatores influenciadores da Ética profissional nas empresas; verificar a importância da Ética profissional e da moral, com enfoque na ética interna da empresa; e demonstrar a relação dos conceitos de ética e moral, visto que as atitudes éticas de uma empresa a levam ao reconhecimento por parte da sociedade que passa a vê-la com olhos de credibilidade e confiabilidade, proporcionando melhor relação interpessoal entre a equipe da empresa e seu público.

Passos (2011, p. 92) explica que:

As organizações éticas buscam, na prática, ser honestas, justas e verdadeiras e democráticas, por uma questão de princípio e não de convivências, muito embora este tipo de agir lhes traga também sucesso e reconhecimento. Sua forma de ser inspira a confiança e a credibilidade dos indivíduos com quem se relacionam e assim, seu empenho e lealdade (PASSOS, 2011, p. 92).

O comportamento correto por parte da empresa a torna confiável pela sociedade e isso ajuda em seu crescimento, pois uma instituição com boa visibilidade atrai público e consequentemente aumenta suas vendas.

Aguilar (1996 apud PASSOS, 2011, p. 93) classifica a empresa ética como:

Aquela que conquistou o respeito e a confiança dos seus empregados, clientes, fornecedores, investidores e outros, estabelecendo um equilíbrio aceitável entre seus interesses econômicos e os interesses de todas as partes afetadas, quando toma decisões ou empreende ações (AGUILAR apud PASSOS, 2011, p. 93).

Pode-se analisar que para que as organizações possam aplicar de maneira eficaz conceitos éticos e morais junto aos seus colaboradores, é preciso que seja estabelecida uma ética interna da organização que oriente suas decisões e permeiem suas relações com a sociedade em geral, destaca Leisinger e Schmitt (2001, p. 54): 
Se uma empresa pode ser considerada como um "coletivo" moral depende antes de tudo do grau de liberdade de ação que ela deixa aos seus membros. Só nas organizações em que as pessoas podem decidir livremente entre várias opções de ação é que uma responsabilidade individual pode ser assumida. Quando não existe a liberdade de ação, ou quando ela é muito pequena, então as virtudes dos membros individuais da organização deixam de ocupar o primeiro plano da análise ética, sendo substituídas pela rigidez da estrutura organizacional e pelos princípios diretores da organização (LEISINGER; SCHMITT, 2001, p. 54).

Para que a empresa conduza bem sua atuação no mercado é essencial sua boa conduta e isso está intimamente ligado a atuação individual de cada colaborador da organização, posto isso demonstra-se imprescindível as normas estabelecidas dentro da empresa que balizarão os comportamentos internos refletindo automaticamente na atuação da empresa no mercado tendo como intuito proporcionar o bom relacionamento entre as pessoas tornando-se necessário o estabelecimento de regras que conduzam o respeito entre os integrantes da sociedade (LISBOA, 2010).

As atitudes de cada colaborador são reflexos de sua vivência pessoal e a aplicação delas nas relações em grupo buscando harmonia compondo assim a essência da ética, no cotidiano as pessoas conduzem em sociedade comportamentos influenciados pelas condições que tem a seu redor, seus valores e crenças individuais, balizados por uma convivência pacífica, a qual constitui o objetivo da ética (LISBOA, 2010).

Como evidencia Nalini (2014, p. 58) “a ética é justamente saber discernir entre o devido e o indevido, o bom e o mau, o bem e o mal, o correto e o incorreto, o certo e o errado", seguindo toda a envoltura da empresa ao se preocupar com o comportamento interno de sua equipe e o reflexo disso na sua visibilidade no mercado, os parâmetros acima constituem minúcias a serem seguidas rigorosamente pela organização.

No intuito de verificar a finalidade proposta com esta pesquisa, formulou-se o seguinte problema: Como a Ética profissional e a moral influenciam nas organizações?

Vazquez (1995, p. 55) argumenta "a função social da moral consiste na regulamentação das relações entre os homens (entre os indivíduos e entre o indivíduo e a comunidade) para contribuir assim no sentido de manter e garantir uma determinada ordem social", em vista disso seguindo regras de bom comportamento por parte da equipe com ela mesma e com todos os clientes proporcionam a empresa boa convivência, visibilidade positiva e com isso alcance dos objetivos com harmonia. 
Os clientes demonstram estar mais exigentes, buscam organizações com condutas e comportamentos retos, que tenham atitude ética em seus negócios, e as empresas atentas a estas exigências têm a seu favor a credibilidade e confiança de seus clientes, proporcionando sucesso a ela no mercado, além de dispor de um ambiente de trabalho mais agradável e funcionários satisfeitos (NALINI, 2014). Desta forma, as empresas que atuam corretamente, tem a seu favor a confiabilidade dos clientes e isso influencia em seu sucesso organizacional.

\section{Considerações Finais}

Constata-se que para que uma organização tenha bons resultados empresarial é essencial que ela tenha atitudes éticas, e para isso também é imprescindível que a empresa disponha de uma equipe de profissionais éticos, garantindo seu sucesso em longo prazo, a atuação ética vai muito além de simplesmente não roubar ou fraudar, é importante o bom atendimento, a boa relação com todos da sociedade, pois a empresa tem que cumprir sua função social auxiliando o desenvolvimento da comunidade onde está inserida.

A moral seguida pelos funcionários das empresas nas suas vivências pessoais influenciam, no comportamento organizacional e com isso é essencial que a empresa busque um equilíbrio entre todas as experiências de seus colaboradores e desenvolva uma ética profissional balizada em seus objetivos institucionais, proporcionando um bom clima organizacional para que a equipe trabalhe harmonicamente.

Este trabalho teve como intuito contribuir para que as instituições notem a grande importância da aplicação da ética profissional dentro e fora das organizações, procurando melhorar seu código de ética empresarial, e assim auxiliar no desenvolvimento pessoal e interpessoal de seus gestores e colaboradores.

É de suma importância a busca pela aplicação da ética e da moral na sociedade e nos ambientes corporativos, portanto torna-se, necessário ampliar os horizontes de pesquisa, sobre o assunto dentro e fora das organizações, para que desta forma as mesmas possam melhorar seus desenvolvimento empresarial e social. 
A ética busca justamente a paridade entre as experiências de cada pessoa e a sua boa aplicação nas relações em sociedade, sendo imprescindível que a organização consiga manter com profissionalismo esse equilíbrio proporcionando sucesso à instituição.

Nota-se nesta análise que com o decorrer do tempo houve uma grande elevação de escândalos de corrupção que eventualmente evidenciaram a falta de ética profissional e social, dentro e fora das empresas, desta forma identificou-se que a sociedade em geral, está apreensiva com o aumento dos indícios de atos antiéticos e imorais, em razão disso os indivíduos estão mais atentos, com as questões ao redor do tema "ética e moral", por isso essa pesquisa teve o propósito de enfatizar que o assunto abordado é importante para o desenvolvimento pessoal e organizacional, enriquecendo desta maneira as virtudes e valores dos indivíduos dentro da comunidade em que vivem.

\section{Referências}

ASHLEY, P. A. Ética e responsabilidade social nos negócios. 2. ed. São Paulo: Saraiva, 2006.

CORTELLA, M. S. Qual é a tua obra? Inquietações, propositivas sobre gestão, liderança e ética. Petrópolis: Vozes, 2009.

CHALITA, G. Os dez mandamentos da ética. 2 ed. Rio de Janeiro: Nova Fronteira, 2009.

DENNY, A. E. Ética e Sociedade. Capivari: Opinião, 2001, p. 276

CERVO, A. L.; BERVIAN P. A.; SILVA, R. Metodologia Científica. 6. Ed. São Paulo: Pearson Prentice Hall, 2007.

GERHARDT, T. E; SILVEIRA, D.T. Métodos de Pesquisa. Coordenado pela Universidade Aberta do Brasil - UAB/UFRGS e pelo curso de graduação Tecnológica - Planejamento e Gestão para o Desenvolvimento Rural da SEAD/UFRGS - Porto Alegre: Editora da UFRGS, 2009.

LEISINGER, K. M.; SCHMITT, K. Ética empresarial; responsabilidade global e gerenciamento moderno. Tradução de Carlos Almeida Pereira.Petrópolis: Vozes, 2001.

LISBOA, L. P. Ética geral e profissional em contabilidade. Fundação Instituto de Pesquisas Contábeis, direção geral Eliseu Martins. São Paulo: Atlas, 2010. 
Id on Line Revista Multidisciplinar e de Psicoloqia

Id on Line Multidisciplinary and Psycology Journal

MORAES, R. Uma tempestade de luz: a compreensão possibilitada pela análise textual discursiva. Ciência \& Educação, v.9 n.2, 2003.

NALINI, J. R. Ética geral e profissional. 4. ed. São Paulo: Revista dos Tribunais, 2014.

PASSOS, E. Ética nas organizações. 1. ed. São Paulo: Atlas, 2011.

STEERS, R. M. Antecedents and outcomes or organizational commitment. Administrative Science Quarterly, 22, 46-56, 1977.

VAZQUEZ, A. S. Ética. 15. ed. Rio de Janeiro: Civilização Brasileira, 1995.

Como citar este artigo (Formato ABNT):

DIAS, Anay F.; NITSCHE, Paloma da S.; DE PAULA, Liliane G.; LAVOR, Anna A A.; SILVA, Antônio C.A. da; RIBEIRO, Mariana E.O.; A Ética Profissional como fator influenciador nas Organizações. Id on Line Revista Multidisciplinar e de Psicologia, 2017, vol.11, n.37, p. 436-448. ISSN: 1981-1179.

Recebido: 01.08.2017

Aceito: 08.08.2017 